\title{
A Descriptive Study on Applicability and Adoptability of Cloud Computing Based Technology in the Global Education Scenario
}

\author{
K. C. Shiva Shankar ${ }^{1}$ and G. T. Jagadeesha ${ }^{2}$ \\ ${ }^{1}$ Assistant Professor, ${ }^{2}$ Research Scholar \\ ${ }^{1 \& 2}$ Department of Studies \& Research in Business Administration, Tumkur University, Karnataka, India \\ E-Mail: jagadeesh.gt36@gmail.com
}

\begin{abstract}
Technology Transformation has given an added advantage among the service providers of the educational institutions to provide unique services to their stakeholders in terms of quality delivery. At the same time, these technological introductions certainly have helped individual learners towards learning and at the same time, institututional stake holders got benefited in multiple ways by certainly enhancing their day to day operations in a most effective and efficient way by the adoption of advent technological sources. The Introduction and adaptation of advanced technology has abruptly raised the quality level of delivering educational services. Due to technological advancement, stakeholders could be benefited through early adoption and also they could be able to bring out the best of it. Technological advancement and usage certainly brings more benefits to the educational institutions by building up such a brand value. Here, in this research paper, the researcher tries postulates the major importance of technology and its need into field of education. Cloud Computing Technology Based Model, Artificial Intelligence, Machine Learning, Big Data are those advanced technology had been widely used in different dimensions of the education and in return it provides higher satisfaction and greater flexibility to all of its stakeholders.
\end{abstract}

Keywords: Cloud Computing Technology, Educational Institutions, Technological Transformation

\section{INTRODUCTION}

In the era of technological competence, every service provider in the service sector would like to offer their services in a unique and modern way of delivering such services; which in turn the service providers utilize this technology as a reliable source to make such differentiation among their fellow competitors (Turoff, M. 1999). In addition to human progress, these technology and management as the major reliant source and main key towards their success. Technology has been taught and practice through formal education vice-versa education has been taught to the above standard level by adopting certain technological innovations, these changes and adoption of technology in educational institutions certainly brought a major change in the way of delivering quality education among their stakeholders. Finally, it is evident that certain innovation and technological practices has brought a major competency among the service providers which certainly paved a way to the changes to the various methods, purpose and perceived potential of education. (Anastasiou, V., Athanasopoulos, C., Sarris, M., Savas, S., Sotiriou, S.A., Tolias, V., 2000) (Athanasopoulos, C., Apostolakis, E.,
Eisenbarth, P., Kalkanis, G.T., Lewinsky, H., Sarris, M.M., Savas, S., Sotiriou, S.A., Sperka, M., Stemmler, H., Tolias, V., Wolf, G. 2000)

In the present scenario of education as a more vibrant sector, changes are happening very frequently due to the advent of new technology, which certainly had a more significant effect among the stake holders who lives across each and every corner of globe. Also, it is been found that these traditional ways of teaching and learning process in education has been completely replaced by new advent and emerging modern technologies. Broad Changes and advent introduction of new technology has created a major impact across all areas of education such as Designing Curriculum, Teaching Methodology, Learning Methodology through Effective and Efficient Assignments etc. (Kaushik Bhakta, Nabanita Dutta, 2016).

Improved and Clear way of communication and also with increased access to Information Technology (IT) among the stake holder's residence, work place environment and educational institutions certainly keeps education as a lifelong learning process. In addition to that Information technology certainly helps in promoting various opportunities of knowledge sharing throughout the world and these in turn had helped various stakeholders of education sector has started to gain up-to-date knowledge and information. As you all know that for effective learning and teaching needs right information which certainly keeps them more competitive. (Kaushik Bhakta, Nabanita Dutta, 2016).

Usages of Information technology are the set of new technological developments that certainly can help the right people with the right information at the right time. Hence, these conceptual papers are trying to postulates the major need and importance of Information Technology (IT) in this global educational sector and there is a strong impact of information Technology (IT) on classroom teaching and learning. (Kaushik Bhakta, Nabanita Dutta, 2016).

\section{NEED OF THE RESEARCH STUDY}

Many Eminent Scholars, Researchers and Academicians have rightly said that both education and learning is lifelong processes, they have no time limit of when to start and stop. 
Learning Process certainly helps the various stake holders in gaining and attaining new experiences in our everyday life. By educating students we would certainly know about various types of information and its respective information content depth. Normally, Information Technology (IT) has the high ability in speeding up information delivery so that this ability can be used and utilized in improving teachinglearning environment. Both faculty members and students are using various advent and modern technologies would certainly help them to achieve specific academic goals. (Aviram, A. 2000)

Emerging Information Technologies have certainly increased the cost of education. For example the use of internet broadband has increased and makes it easy for stakeholders to access academic information on time and it's available for access at all time, so that whenever and wherever these information needed for stake holders, these Information Technology (IT) had certainly provided that greater kid of sophistication to them. These Information Technology as a reliant and evident source, which acts as the bridge between faculty and their students in a most effective and efficient platform for sharing their information online at anytime they need to do so. (Aviram, A. 2000)

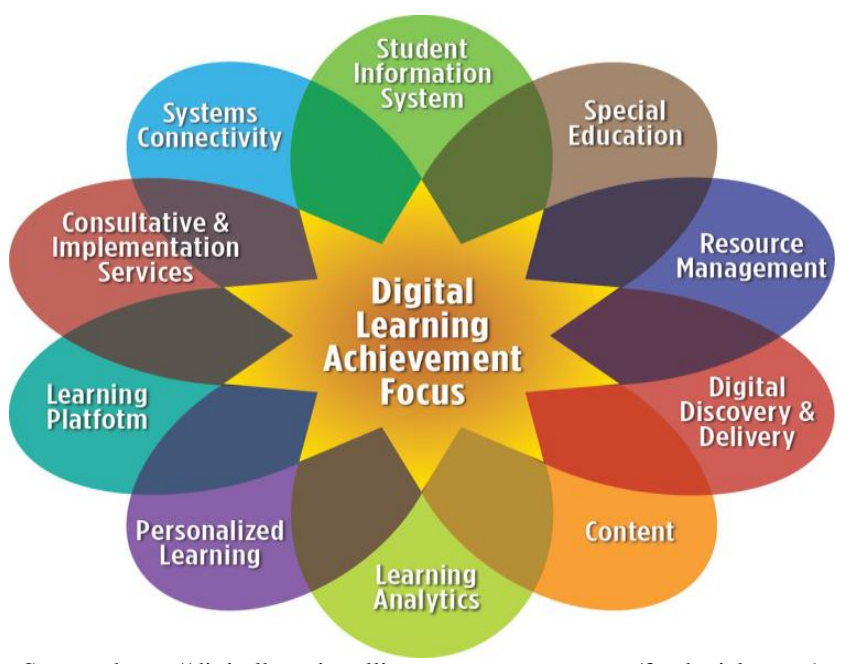

Source: https://digitallearningalliance.squarespace.com/for-legislators-1 Fig. 1 Digital Learning Achievement Focus through Technological Transformation in the Educational Sector

Today, Various Emerging Technology (Cloud Computing Technology Model, Artificial Intelligence (AI), and Internet of Things (IoT's), Machine Learning) in the education had certainly raised the competency among their stakeholders and at the same time, the delivery of such education could be delivered with utmost differentiated and satisfiable manner. These service providers in the field of education, who had started to adopt these technologies, which would certainly take away the greater advantage associated with it and at the same time certain service providers due to the technological Upgardation they are forced to follow, these late adopters also would get an certain sophistication but they would not enjoy as long as benefits received by early adopters of technology in education sector. (Aviram, A., \& Talmi, D., 2005)
Hence, there is a need of more number research study majorly focusing on various technological transformation and its adaptation challenges and opportunities needs to be discussed so that it will bring a major change in the field of education and as well as among the educational institutions offering such quality education as their premier service. Technological Transformation has certainly provided a new paradigm and dimension in the field of education with more competitiveness and sophistication can be offered to it which makes greater differentiation to its stake holders (Aviram, A., \& Talmi, D., 2005)

\section{REVIEW OF LITERATURE}

Lin, Yen-Ting \& Wen, Sophia Ming-Lee \& Jou, Min \& Wu, Din-Wu. (2014) performed a research study focused mainly on the cloud-based learning environment for developing student reflection abilities. Wherein Reflection here refers to the various impact that on student's interactions with various learning materials. At the end of the research study, researcher has found that good reflection abilities certainly allow students to attain better motivation through earning, simultaneously students would be able to develop high comprehensive, and performance based education that will certainly enhance their reflective ability as a whole. Certainly, Researchers found that there is a huge impact in the way we deliver the educational services accordingly makes use of that technology which would create big impact among the teaching and learning process.

Jou, Min \& Shiau, J.-K. (2012) carried out a research study on the development of a web-based self-reflective learning system for technological education, wherein in this research study primarily aimed at developing a web-based online self-reflective learning system, this would be certainly able to enhance students' learning through this advent industrial technology.

SIU, K.W.M, (2002) carried out a research majorly focusing on the Impact of new technology on teaching and learning especially in technology education, whereas the researcher tried to identify the various opportunity or threat prevailing in the technology education in Hong Kong and certainly the researcher could be able to find and identify the various opportunities and challenges in Honk Kong, finally the outcome of this steady helped many stakeholders in a most predominant manner. Also in another dimension it has provided the researcher the technological gap and educational changes needed in order to improve their standard of technology education in Hong Kong.

\section{IMPACT OF TECHNOLOGY ON TEACHING AND LEARNING}

Technology is forcing speedy changes in pedagogy that can't be neglected. Technology Competency Standards (TCS) and High competition of Digital Learning are two major key factors that certainly create a need of urgency for technology integration into higher education field. It's been 
right said by various experts that technology competencies for higher education faculty is immaterial. Various Researches suggests that standards are inevitable and they do expect a dynamic growth in Digital Learning Platform. (Arminio, J. 1999).

However, research also suggests that integration will require more than just establishing competencies. If an educational institution wants to remain competitive in the new digital millennium, they must effectively and efficiently need to integrate these modern technologies into the classroom. This certainly make educational institutions to develop a modern cohesive training programs with an greater emphasis on learning and provide more adequate technical support that will certainly assist faculty members in integrating technology into content delivery. (Moersch. C, 1995).

Therefore, Faculty Development Centres must be established to train faculty to use these modern advent technology, also need to show them how to use it effectively in the classroom, and offer just-in-time technical support then and there where you can find the effectiveness. (Webster, J., \& Hackley, P. 1997) that Faculty Development Center must host many onsite personnel programmes with a wide variety of materials and methods for teaching and learning (i.e., videos based training, computer-based Skill training, online courses, Quality tutorial Materials, Web Based seminars, best benchmarking practices, help desk). (Privateer, P.M. 1999)

TABLE I TRADITIONAL LEARNING ASSUMPTIONS VS MODERN LEARNING ASSUMPTIONS

\begin{tabular}{|l|l|}
\hline \multicolumn{1}{|c|}{$\begin{array}{c}\text { Traditional Learning } \\
\text { Assumptions }\end{array}$} & \multicolumn{1}{|c|}{$\begin{array}{c}\text { Modern Learning } \\
\text { Assumptions }\end{array}$} \\
\hline $\begin{array}{l}\text { People transfer learning with } \\
\text { ease by learning abstract and } \\
\text { decontextualized concepts. }\end{array}$ & $\begin{array}{l}\text { People transfer learning with } \\
\text { difficulty needing both } \\
\text { content and context learning. }\end{array}$ \\
\hline $\begin{array}{l}\text { Learners are receivers of } \\
\text { knowledge }\end{array}$ & $\begin{array}{l}\text { Learners are active } \\
\text { constructors of knowledge. }\end{array}$ \\
\hline $\begin{array}{l}\text { Learning is behavioristic and } \\
\text { involves the strengthening of } \\
\text { stimulus and response. }\end{array}$ & $\begin{array}{l}\text { Learning is cognitive and in a } \\
\text { constant state of growth. }\end{array}$ \\
\hline $\begin{array}{l}\text { Learners are blank slates } \\
\text { ready to be filled with } \\
\text { knowledge. }\end{array}$ & $\begin{array}{l}\text { Learners bring their own } \\
\text { needs and experiences to } \\
\text { learning situations }\end{array}$ \\
\hline $\begin{array}{l}\text { Skills and knowledge are best } \\
\text { acquired independent of } \\
\text { context. }\end{array}$ & $\begin{array}{l}\text { Skills and knowledge are best } \\
\text { acquired within realistic } \\
\text { contexts. }\end{array}$ \\
\hline
\end{tabular}

Training must not only be technical but it also must include teaching faculty about learning modern theories and models, then they need to recognize their own learning styles for delivering such things to their students in order to maximize learning experiences in the classroom. The Most widely used technology in the field of Education is

1. Cloud Computing Technology Model

2. Artificial Intelligence (AI), and

3. Internet of Things (IoT's), Machine Learning Tools and Techniques
A. Cloud Computing Technology Model: In India, Most of the educational institutions have become highly dependent more on Information and Communication Technology (ICT) Tools. These Information and Communication Technology (ICT) Tools provides unique solutions to their problems and also they regularly service their requirements.

These periodical services and on time solutions are progressively provided, maintained, and stored using Internet Services, where it can be accessed at any time using web browsers by both teaching non-teaching staff and students and faculty members. These modern technological services are not available cheaply or freely to education; often with most of these educational institutions spend a lot of money on the various resources in order to provide such quality services to their major stakeholders. Thus, Cloud Computing Technology Model has a greater and significant usage in the field of education, by such introduction of technology, the field of education started to flourish on different dimensions and providing a greater sophistication to all major stakeholders. (Moersch, C. 1995) (Schulman, A.H., \& Sims, R.L. 1999)

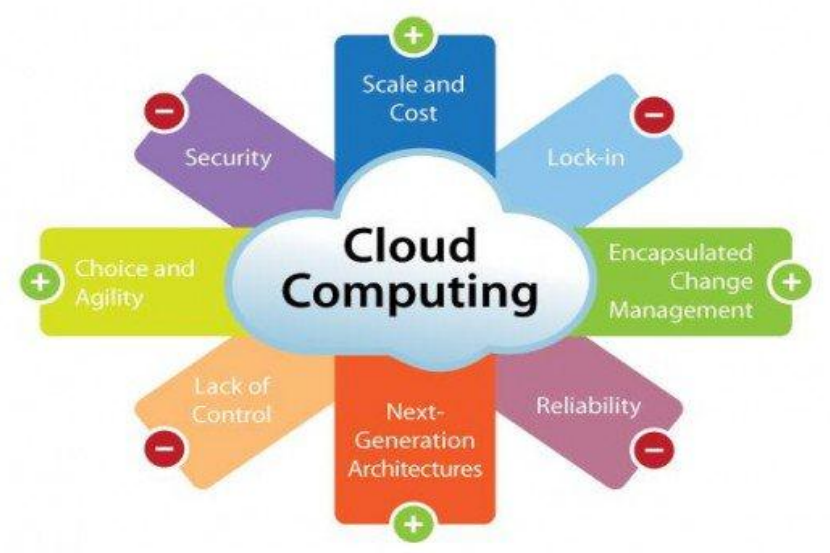

Sources: https://hubpages.com/technology/cloud-computing-architecture Fig. 2 Cloud Computing Architecture

B. Role of Artificial Intelligence (AI) In the Field of Education: The Role of Artificial Intelligence (AI) in the field of Education has become a dominant factor in today's challenging teaching and learning environment. The contribution of Artificial Intelligence (AI) certainly provides sophistication to modern learners who started to enjoy the way of learning as an experience. Artificial Intelligence in education provides more in depth learning with most advanced techniques, wherein at times it helps the stake holders in taking important decisions and also service providers started to widely utilize such technology expertise in order to provide a service differentiations and to provide a unique kind of experience to its stake holders.

C. Internet of Things (IoT's) and Machine Learning Tools and Techniques: Educational Institutions and Service provider's needs to keep themselves up with the increasingly tech-savvy emerging generations. IoT-enabled education solutions, from smart boards to security applications, are allowing the education sector to transform itself for the future. 


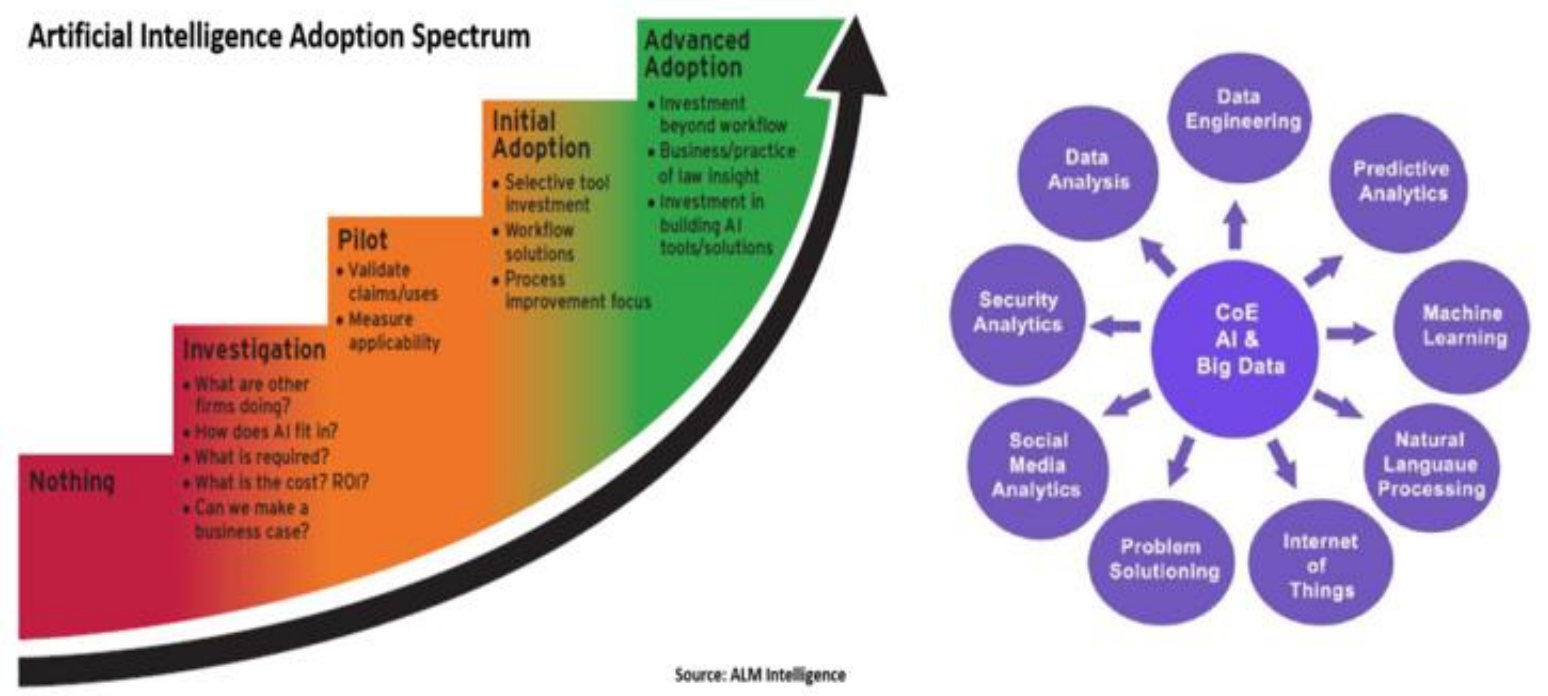

Sources: http://www.aianalyticshub.com/Centre\%200f\%20Excellence\%20AI\%20Analytics.php

Fig. 3 Challenges that exist in business today - to build most intelligent systems and big data analytics solutions

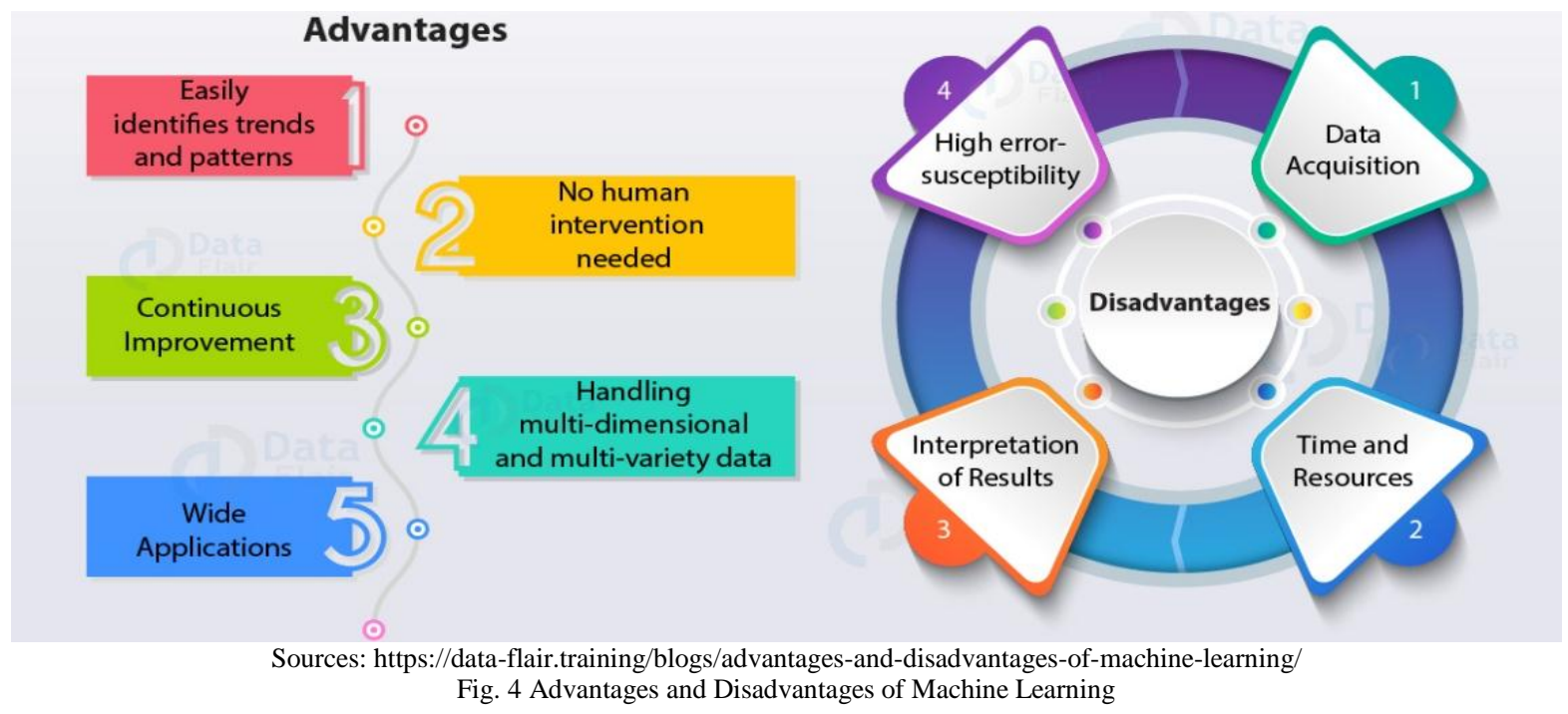

\section{CONCLUSION}

In the Conclusion the researcher would like tell that technological advancement certainly helps various stake holders and the same time it provided a kind of advantage to each of them. As Experts said earlier, one who adopts a technology earlier certainly would be able to enjoy all the benefits out of it and at the same time they could be able to view the various challenges out of it by facing such so and then by overcoming such difficulty a unique competitiveness would be identified by them. Later on such technological adaptation helps to build their brand and be able to build a sustainable competitive advantage out of it. Hence the researchers would like to conclude that technology has to be widely been used among various functionalities of business irrespective of considering their expected outcomes, wherein by going through long way one could be able to overcome their challenges and finally they could be successful by making use the best of such technology.

\section{REFERENCES}

[1] V. Anastasiou, C. Athanasopoulos, M. Sarris, S. Savas, S.A. Sotiriou, V. Tolias, "The School of Tomorrow: A school open to the world, examples of elements of good practice", in Proceedings of the EDEN Fourth Open Classroom Conference, Barcelona, Spain, Nov. 19-21, 2000.

[2] C. Athanasopoulos, E. Apostolakis, P. Eisenbarth, G.T. Kalkanis, H. Lewinsky, M.M. Sarris, S. Savas, S.A. Sotiriou, M. Sperka, H. Stemmler, V. Tolias, G. Wolf, Implementation of Scientific Methodology and Modeling Tools in an Open Classroom (Ages 1017), in Proceedings of the EDEN Fourth Open Classroom Conference, Barcelona, Spain, Nov. 19-21, 2000.

[3] A. Aviram, "The Integration of ICT and Education: From 'computers in the classroom' to mindful radical adaptation of education systems to the emerging cyber culture, Journal of Educational Change, Vol. 1, pp. 331-352, 2000.

[4] A. Aviram and D. Talmi, "The Impact of Information and Communication Technology on Education: The Missing Discourse between Three Different Paradigms", E-Learning and Digital Media, Vol. 2, No. 2, pp. 169-191, 2005. https://doi.org/10.2304/elea. 2005.2.2.5

[5] Kaushik Bhakta and Nabanita Dutta, "Impact of Information Technology on Teaching-Learning Process", International Research 
K. C. Shiva Shankar and G. T. Jagadeesha

Journal of Interdisciplinary \& Multidisciplinary Studies (IRJIMS), Vol. 2, No. 9, pp.131-138, December 2016.

[6] Lin, Yen-Ting \& Wen, Sophia Ming-Lee \& Jou, Min \& Wu and Din$\mathrm{Wu}$, "A cloud-based learning environment for developing student reflection abilities", Computers in Human Behavior, Vol. 32, pp. 244252, 2014. DOI: $10.1016 /$ j.chb.2013.12.014

[7] Jou, Min and J. K. Shiau, "The development of a web-based selfreflective learning system for technological education", Turkish Online Journal of Educational Technology, Vol. 11, pp. 165-171, 2012

[8] K.W.M, SIU, "Impact of new technology on teaching and learning in technology education: opportunity or threat?", Design \& Technology Association International Research Conference, pp. 29-37, 12-14 April, 2002.

[9] J. Arminio, "The Virtual Campus: Technology and Reform in Higher Education", Journal of College Student Personnel, Vol. 40, No. 1, pp. 114, 1999.

[10] C. Mock ford and H. Denton, "Assessment Modes, Learning Styles, And Design And Technology Project Work In Higher Education", The Journal of Technology Studies, 1998. [Online]
Available: http://scholar.lib.vt.edu/ejournals/JTS/Winter-Spring1998/mockford.html

[11] C. Moersch, "Levels of Technology Implementation: A Framework for Measuring Classroom Technology Use", Learning \& Leading with Technology, Vol. 23, No. 3, Nov. 1995. [Online] Available: http://www.iste.org/L\&L/archive/vol26/no8/supplements/moersch/m oer-sch.html

[12] M. Turoff, "Education, Commerce, Communications: The Era of Competition", Web Net Journal, pp. 22-31, January-March 1999.

[13] J. Webster and P. Hackley, "Teaching Effectiveness in TechnologyMediated Distance Learning", Academy of Management Journal, Vol. 40, No. 6, pp.1282-1309, Dec. 1997.

[14] A. H. Schulman and R. L. Sims, "Learning in an online format versus an in-class format: An experimental study", T.H.E. Journal, June 1999. [Online] Available: http://www.thejournal.com/magazine/ vault/A2090.cfm

[15] P.M. Privateer, "Academic Technology and the Future of Higher Education: Strategic Paths Taken and Not Taken", The Journal of Higher Education, Vol. 70, No. 1, pp.60-79, January/February 1999. 